\title{
The Development of Robotic Process Automation (RPA) For the Efficiency of Back Office Operations at Bank Muscat
}

\author{
Ibrahim Mohammed \\ Nupur Goel
}

\author{
Middle East College \\ Middle East College
}

\begin{abstract}
Achieving operational efficiency is a concern for the financial institutions especially banks. Robotic process automation is software that can be used to automate repetitive, rule-based processes. Employees in the bank's back-office operations deal with high-volume of data every day. RPA is a new wave of technologies that is true to be adopted to improve efficiency, accuracy, productivity and reduce the operational costs. The purpose of this study is to expose the development of robotic process automation (RPA) within the bank for the efficiency of back-office operation processes. The survey was established as collected primary data for Bank's employees to introduce RPA and analyses the current state of back-office operational. Additionally, interview was conducted within to identify the requirements of developing RPA based on the bank's needs. Also, the challenges of adopting RPA has been analyzed within the present environment of the bank. The secondary data were collected from literature reviews on the RPA benefits and it is successful implementation within banking industry in order to highlight the positive implication of developing RPA and support primary data collected. The results indicate to develop RPA, the bank needs to analyses the basic requirements and overcome the challenges that would obstruct the developing of RPA. Also, bank should spread the knowledge of RPA with its benefits and involve the employees for the developments and training. This research will help the banks in Oman to make decisions on moving towards automation and digitalization to improve their quality of products/services that can be achieved by having efficient back-office processes.
\end{abstract}

\section{Introduction}

The change in technology began with digitalizing and mobile technology. Hence, these technologies been disruptive by other technologies, such as big data, cloud technologies, internet of things (IoT), social media, automation robotics, and others (KAYA, TURKYILMAZ, \& BIROL, 2019).

In order to survive in the current competitive market, banks should have a way to deliver the best customer experiences. Internally, the challenges in most of the industries and especially banks are to maximize the efficiency and decrease the costs as much as possible and have a high level of security. To reach this demand, robotic process automation (RPA) is becoming a powerful and operative tool. Robots is a machine which is designed to be electromechanically programmed by a computer that is capable to carry out of complex series of actions automatically (Madakam, M. Holmukhe, \& Jaiswal, The Future Digital Work Force: Robotic Process Automation (RPA), 2019). As known, the process is the conversion from input to output. on the other hand, automation is a technique of making any process as automated. Simply, robotic process automation is the next wave of automation that will replace human labor to automated tasks that will be conducted by software. Bank representative bargain with influencer information from the client and manual forms are inclined to have mistaken. Banks around the world are considering RPA to play down the manual handling of this colossal information to maintain a strategic distance from blunders. Preparing information physically to the time-devouring assignment. Automated prepare mechanization has moreover significantly streamlined a wide assortment of back-office forms that once hindered down bank laborers. By moving much of these dull, manual assignments from human 
to machine, banks have been able to essentially decrease the require for human association, which has had a coordinate effect on everything from execution and productivity levels to staffing issues and costs (C. Lacity \& P. Willcocks, Robotic Process Automation at Telefónica O2, 2016).

\section{Problem Statement}

Banks always looks for enhancing customer experience and services by adopting technology and providing many digitalize customer-facing and front-end operations solutions. However, there are still many processes at the bank rely on people and paper. Often, back-office operations require people to process many of customer requests manually. The back-office operating area that will process orders, claims, payments, etc, cannot be done equally every day and it might be combined with complex work which will create an issue such as process bottleneck and slowness in customer services which require to be simplified. Bank employee deals with voluminous customer data and manual process susceptible to have errors and it is time-consuming tasks. These routines tasks and workload will reduce employee's productivity instead of focusing more on doing value tasks that would improve their engagement and work efficiency. Moreover, banks are underneath strain to optimize costs in different ways.

In response to this problem, this study proposes the development of Robotic Process Automation (RPA) in Bank Muscat at back-office operations.

\section{The Objective of the Study}

\section{This study will pursue the below objectives:}

- To find the requirements of developing Robotic Process Automation (RPA) at Bank Muscat.

- To analyze the challenges of developing Robotic Process Automation (RPA) within Bank Muscat

- To study the implication of developing Robotic Process Automation (RPA) for Bank Muscat staff and customers

- To find the process to train the employees for the using of Robotic Process Automation (RPA) within bank Muscat applications.

\section{Review of the Related Literature}

\section{Definition of Robotic Process Automation (RPA)}

Robotic Process Automation is a term which means automation of service tasks performed by a human. Moreover, in business processes, RPA is referring to configured software to perform human tasks, such as transferring data from multiple inputs to record the captured information into other systems. The software is seeing as a robot because it replaces the tasks that are done by human resources (Madakam, M. Holmukhe, \& Jaiswal, The Future Digital Work Force: Robotic Process Automation (RPA), 2019).

"Robotic process automation is the application of technology that allows employees in a company to configure computer software or a "robot" to capture and interpret existing applications for processing a transaction, manipulating data, triggering responses and communicating with other digital systems"

(Accenture, 2018). 


\section{The Benefits of Developing Robotic Process Automation (RPA)}

\section{a. Cost Reduction and Improve Profitability}

According to (Accenture, 2018), RPA can create cost-saving by 25-50\%, enables execution by $24 \times 7 \times 365$ and provides error-free compared to human works and capacity. Business Process Outsourcing (BPO) service provider employed full-time human employee to process insurance benefits through the application which took around 12 minutes to do the same. On the other hand, automation software completed the process within $1 / 3$ of the same time with triple transaction volumes. Moreover, by automating a single process, providers achieved significant return on the investment within six months. Shifting most of the processes to be done by RPA will eliminate manual processes that excess time and resources. Subsequently, organization's margins will improve. The flexibility of robotic process automation allows the employees to fully or partially dependent on the software to accomplish their tasks. For instance, accounting and finance specialists can rely on RPA and spend their time taking high-level tasks and strategic activities. However, companies will save costs by leveraging robotics to complete high transactional jobs and repetitive tasks.

\section{b. Improve Efficiency}

RPA would provide improvement of service deliveries through increasing of production, accuracy and reducing of cycle time and the need for providing continues training for employees. IT staff automation tool suite for the following purposes: initial investments and operations result improved the operational efficiency as it takes $60 \%$ time and effort to solve IT problems without human intervention. Also, RPA will improve IT infrastructure operational by improving management, monitoring and reporting of the devices which will reduce the need of recurring support effort so, consequently the labor cost will decrease, and the efficiency of IT staff will increase (Accenture, 2018). Robotic process automation executes tasks speedily which will boost the processing frequency and efficiency (Madakam, M. Holmukhe, \& Jaiswal, The Future Digital Work Force: Robotic Process Automation (RPA), 2019).

\section{c. Enhance Customer Experience}

Nowadays all the companies are concentrating on providing excellent services and products to its customers. Back-office operations processes may not affect front office tasks which are facing the customers but if RPA been used within the back-office operations to automate the repetitive tasks and high volume of data, this will help employees to inability to focus to deliver high quality of services and products to the customers so, the same will results in meeting customer satisfaction and therefore, improving customer experience.

\section{d. Data integration and compliance}

As there are many systems and applications used by the organizations, hundreds of logs will be generated for each system. Checking logs for each application will result in generating gaps. RPA is easy to configure and can be integrated with the existing systems without any programming skills required and users can be trained within few weeks (Accenture, 2018). This will help in recording all required combined logs to be provided an organized way. Also, RPA can handle compliance issues by following regulatory and providing audit trail history.

\section{e. High accuracy}

According to (Madakam, M. Holmukhe, \& Jaiswal, The Future Digital Work Force: Robotic Process Automation (RPA), 2019), robotics process automation has many of advantages such as, operational accuracy by inputting the right data and avoid any human intervention, employee's moral improvement, increasing productivity by having faster process cycles time compared to manual 


\section{Journal of Student Research}

Fourth Middle East College Student Research Conference, Muscat, Sultanate of Oman

processes, low technical barriers as no programming skills need it and consistency by performing routines tasks without any interruption which will results in reliability and reducing on underlaying of legacy systems that burden in IT.

\section{Successful Implementation of RPA in the Banking Sector}

According to (Partnership, 2019), and based on P\&S Market Research, the adoption of RPA in banking sectors showed significant successful achievement. The Bank of New York Mellon began with RPA in 2016 with processing trade settlement procedures that include clearing trades, conducting research on orders and addressing discrepancies. BNY Mellon observed that though automation the same procedure been done in a quarter of a second on the other hand it was taking for staff from five to ten seconds to reconcile a failed trade. BNY Mellon noted the benefits of RPA as $88 \%$ improvement in the time of processing transactions and validating accounts for closure with around $100 \%$ accuracy. Also, the bank noticed that the development of RPA across different systems allowed their employees to be dedicated more on controlling operational quality and outliers. Moreover, RPA has been increased the bank efficiency, reduced costs and improved the operational process speed and accuracy.

BB\&T Corporation is one of the largest financial companies which invest up to $\$ 50$ million in fintech companies as a significant strategic revolutionary for company's digital business transformation (Corporation, 2019). The company stated in their 2017 annual report (BB\&T, 2017)that they initiated robotics in their bank services to improve their profitability. Pega company ( RPA solutions provider) listed BB\&T as one of its RPA client (Pega, 2019).

SunTrust Bank has been adapted RPA in 2016, and the results delivered high speed in processing transactions as it is improved by $3.8 \mathrm{x}$ as average. Additionally, average training time has been improved by $4 \mathrm{x}$ and the average error rate has been reduced by $65 \%$. SunTrust is investing in automation of its business process aiming for improving the efficiency and give for its employees more time to focus on high value-added tasks (SunTrust, 2017).

Danske Bank has deployed RPA into its operations and back-office processes such as corporate action processing and income payment. The implementation of RPA in the bank resulted in a $40 \%$ decrease in average processing time, $45 \%$ growth in employees' ability to focus on customers activities and eradication human error elimination (SHOJAI, 2017).

According to 2017 annual report of KAS Bank, RPA been implemented in 2016 for the aim to have an effective and efficient client process to reduce human intervention and eliminate errors. KAS bank has implemented around 15 automated processes which resulted in improving customer services levels as response and throughput time has been reduced. Also, standardized checks and the error-free process has improved the bank's compliance. From customer perspectives with RPA implementation, KAS bank been able to provide fast, effective and high quality automated end-toend processes which allowed the bank staff to focus to deliver innovative and high quality of products and services (BANK, 2017).

Deutsche Bank reported 30-70\% of automation been integrated with its software which observed with a decrease in time required to train employees (Madakam, M. Holmukhe, \& Jaiswal, The Future Digital Work Force: Robotic Process Automation (RPA), 2019). CB\&S Bank developed RPA to automate its daily, weekly and monthly processes which resulted in a reduction of the time that requires to process line of credit from 2-3 hours to just one hour (KAYA, TURKYILMAZ, \& BIROL, 2019).

\section{Challenges of Developing Robotic Process Automation (RPA)}

Developing new technologies in any organization could be challenging due to the legacy structured 


\section{Journal of Student Research}

Fourth Middle East College Student Research Conference, Muscat, Sultanate of Oman

system and processes. According to (Hallikainen, Bekkhus, \& L. Pan, 2018), for RPA internal adoption, there are some points to be considered. For an instant, before implementing RPA for a process it should be chosen carefully. Organizations should establish a baseline to check the time that is taken to perform a process manually that would help to measure the improvement after implementation of RPA. Additionally, the chosen processes should be rule-based and consume time in order to get a significant impact after automating the same. Business professionals should believe that automation and robots should be as assistance that will save their time and helps in improving the quality of their work. Moreover, organizations should prepare their IT- department and develop RPA capabilities by being involved in developing business case, configuring applications, development, testing and production phases of RPA. Also, IT- department should build capabilities including effective collaboration between business users and RPA programmers, understating business process and translate the same into rules, interpret reports that will be generated from the robots and find ways to make use of these data for improving performance.

RPA is can be used to automate rule-based and structured tasks, and not to be intelligent in the sense, RPA cannot be integrated to perform complicated tasks (KRUSKOPF, et al., 2019).

Implementing new technology within the organization would be stressful for employees as they would be shifting from their responsibilities to work on new processes. The challenge here of implementing automation would-be employees' resistances. Developing RPA will lead to changing in the existing IT infrastructure. For most large organizations the IT infrastructure is centralized and limited with many securities concerns. For that developing RPA will require a responsible team in IT that will investigate all the automated processes. Lack of responsible team and leadership in analyzing the business process which requires for automation is a challenge for developing RPA within the organization. Also, adopting RPA should be under a clear business case that involves approvals from the respective management team as this will avoid any conflict in the plan of transforming to automation. The limited application used for automation won't help in having full automated process. Also, RPA is new technology and it is hard to find customized solution for it to satisfy enterprises requirements (Parvez \& Agaram, 2019).

Developing RPA will require training and according to OpusCapita training is required as a basis for all employees and full dedicated training for IT staff (Hallikainen, Bekkhus, \& L. Pan, 2018).

\section{Employees Training with Developing RPA}

RPA is a software tool that does not require any programming or coding skills. Thus, any employees can be trained as it is not specified to deal while developing with IT team as much as it requires the business team to be involved while developing and using it. Starting small with new technology is the safe and best way to move through digital transformation and will be easy to be managed by the employees. Additionally, employees should be engaged in the process of developing RPA to understand the use, important and the value that RPA will add for their daily work as this will provide a confidant for the users to accept the RPA as new technology that won't be replacing them but instead of it would help then and they would be more focused to work on high-value tasks. RPA will automate the manual employee processes, so employees' efforts will be reduced for the manual processes, but to increase productivity, employees should be involved in investigating on new interfaces and maintenance of the robots. Creating center of excellence would be important for organizations that would like to expand its experience with RPA that will be focused to improve employees' skills to configure, install, and integrate RPA within human workflow (Griviței, 2018).

\section{Research Methodology}

Data collection is a method used to gather all the required information from the relevant resources and finding responses. In this research, primary and secondary types of data have been used. For primary data, the questionnaire has been distributed to 100 employees of Bank Muscat in Sultanate of Oman. The interview was conducted to specific answers related to the current environment of 
Bank Muscat back-office operations.

\section{Presentation and Analysis of Data}

A questionnaire has been conducted using the SurveyMonkey tool which been distributed among Bank Muscat employees. The survey contained 10 questions and the total responses were 104 responses. The actual responses were 100 responses as this research can rely on it, were 4 responses have been skipped.

\section{Descriptive Analysis}

For a questionnaire, a descriptive analysis is conducted to describe the collected data by providing simple summaries of the sample and measurement. Frequency analysis has been done as a part of the descriptive analysis to measure the occurrence of each variable with provided details on the mean and standard deviations. Below are the 10-interview question which been conducted as a survey.

\section{1-Are you familiar with Robotic Process Automation (RPA)?}

1. Yes, I have heard about it

2. No, I am not familiar with it

2-Are there any involvement of applications/systems in your daily work operations?

1. Yes

2. No

3-What is the frequency that you are dealing with a high volume of data?
1. Daily
2. Weekly
3. Monthly
4. Yearly

4-What is the most task that consumes time while accessing applications?

1. Copying and pasting activity from different applications

2. Inputting/filling data within the application

3. Processing transactions

4. Data reconciliation and validation

5. Checking and Collecting logs from applications

5-What percentage does your daily operations involve manual, structured and repetitive inputs?
1. $25 \%$
2. $35 \%$
3. $45 \%$
4. $65 \%$

6-Do you agree or disagree with the following statement: Introducing the new technology (RPA) will maintain the accuracy of data and human errors?

1. Strongly agree 
2. Somewhat agree

3. Neither agree nor disagree

4. Somewhat disagree

5. Strongly disagree

7-What are the challenges to the bank's ability to drive through digital transformation and automation?

1. Lack of investment

2. Complexity to the current state / legacy environment

3. Resource availability \& appropriate skills

4. Poor accountability / unclear roles \& responsibilities

5. Failure to build a strong business case for change

8-What is your forecasting if automation applied in bank's applications/systems?

1. Profit and productivity increase

2. Profit and productivity decrease

3. No change

4 .

9-Do you agree or disagree with the following statement: Automation will increase employees work efficiency

1. Somewhat agree

2. Neither agree nor disagree

3. Somewhat disagree

4. Strongly disagree

10-Do you agree or disagree with the following statement: implementing RPA (automated processes) at the bank will require staff training on the same.

1. Somewhat agree

2. Neither agree nor disagree

3. Somewhat disagree

4. Strongly disagree

\section{Inferential Analysis}

The inferential analysis is statistical analysis that is different than the descriptive analysis as it used to conclude the results by answering the questions about the population using hypothesis test, regression, and correlation which are under inferential analysis category. In this research different analysis been used for the same hypothesis that been set for this research.

\section{Correlation Analysis}

Correlation analysis is a statistical analysis that describes 


\section{CORRELATIDNS}

CORRELATION

NARIABLES $=0907$

IPRNT = ONETAIL NOSIG,

\begin{tabular}{|c|c|c|c|}
\hline & & $\begin{array}{l}\text { Oo you agree or disgoree with the following statement: } \\
\text { Automation will increase employeses' work efficiency }\end{array}$ & $\begin{array}{l}\text { What are the challenges to the bank's ability to drive } \\
\text { through digital transiomation and automation? }\end{array}$ \\
\hline $\begin{array}{l}\text { Do you dogree ar disogree with the fallowing statement: } \\
\text { Automation will increasce employeas' work efficency }\end{array}$ & $\begin{array}{l}\text { Pearsan } \\
\text { Correlation } \\
\text { Sig. }(1 \text {-tailed }) \\
N\end{array}$ & 1.00 & $\begin{array}{l}.94 \\
.000 \\
100\end{array}$ \\
\hline $\begin{array}{l}\text { What are the challenges to the bark's ability to divive } \\
\text { through dightal transtormation and autamation? }\end{array}$ & $\begin{array}{l}\text { Pearson } \\
\text { Correlation } \\
\text { Sig, (1-tailed) } \\
\text { N }\end{array}$ & $\begin{array}{l}.94 \\
.000 \\
100\end{array}$ & 1.00 \\
\hline
\end{tabular}

Figure 1. Correlation Analysis

the relationship between variables. The correlation coefficient $r$ is the measurement of correlation which ranges between +1 and -1 . +1 indicates a positive correlation as one variable increase the second variable will also increase. While -1 indicates for negative correlation as one variable increase the other variable will decrease. Zero correlation coefficient indicates that there is no correlation between the selected variables.

In this research, a correlation has been tested for the below hypothesis to examine the relationship between the independent variable (the challenge to the bank's ability to drive through digital transformation with automation) and the depended variable (employees' work efficiency).

As per Pearson's correlation to assess the relationship the challenge to the bank's ability to drive through digital transformation with automation and employees' work efficiency. Figure 21 shows the Pearson correlation value which is 0.94 which indicates a positive correlation between the challenge to the bank's ability to drive through digital transformation with automation and employees' work efficiency. Additionally, correlation coefficient indicates the strength and direction of a linear relationship and the value of 0.94 strong positive linear relationships between the challenge to the bank's ability to drive through digital transformation with automation and employees' work efficiency.

\section{Crosstab Analysis}




\author{
CROSSTABS \\ CROSSTABS \\ ITABES $=Q 9$ BY QY \\ IFORMAT =AVALUE TABLES PNOT \\ ISTATISTICS=CHISQ \\ ICELS=TOTAL.
}

Summary.

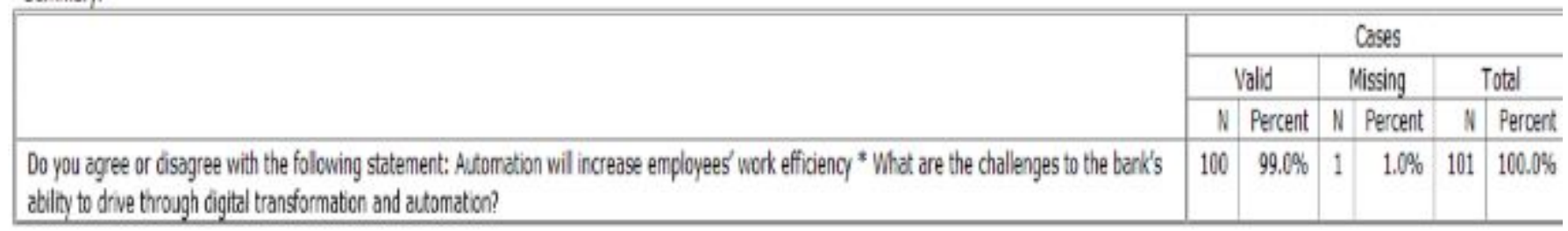

Do you agree or dsagree with the following stotemert: Automation will increase employees' work effidenc; * What are the challenges to the bank's abilty to drive through digtal trarsformation ard automation? [total \%).

\begin{tabular}{|c|c|c|c|c|c|c|}
\hline \multirow[b]{2}{*}{ 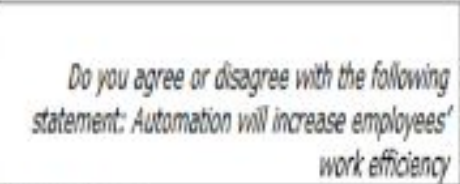 } & \multicolumn{5}{|c|}{ What are the challenges to the bank's ability to drive through digtal itransformation and automation? } & \multirow[b]{2}{*}{ Total } \\
\hline & $\begin{array}{l}\text { Lad of } \\
\text { investment }\end{array}$ & $\begin{array}{l}\text { Complesty to the oureert } \\
\text { state / legacy envionment }\end{array}$ & $\begin{array}{l}\text { Resource avaizbility } \\
\text { \& approprizte sbills }\end{array}$ & $\begin{array}{l}\text { Poor accountability / undear } \\
\text { roles \& resporsibilites }\end{array}$ & $\begin{array}{l}\text { Falure to build a strong } \\
\text { business case for charge }\end{array}$ & \\
\hline Stroncy agree & $14,00 \%$ & $24.00 \%$ & $.00 \%$ & $.00 \%$ & $.00 \%$ & $38.00 \%$ \\
\hline Agree & $.00 \%$ & $.00 \%$ & $42.00 \%$ & $.00 \%$ & $.00 \%$ & $42.00 \%$ \\
\hline Neither agree nor dsagree & $.00 \%$ & $.00 \%$ & $1.00 \%$ & $13.00 \%$ & $.00 \%$ & $14.00 \%$ \\
\hline Disagree & $.00 \%$ & $.00 \%$ & $.00 \%$ & $.00 \%$ & $5.00 \%$ & $5.00 \%$ \\
\hline Strongly discogee & $.00 \%$ & $.00 \%$ & $.00 \%$ & $.00 \%$ & $1.00 \%$ & $1.00 \%$ \\
\hline Total & $14.00 \%$ & $24,00 \%$ & $43,00 \%$ & $13.00 \%$ & $6.00 \%$ & $100.00 \%$ \\
\hline
\end{tabular}

\begin{tabular}{|c|c|c|c|}
\hline Statitictic & Vace & df & Asmo, Sig (2-tailed) \\
\hline Pearson Chi-Square & 290.70 & 16 & .000 \\
\hline Likelihood Ratio & 225.72 & 16 & .000 \\
\hline Linear-by-Lirear Assodiation & 87.64 & 1 & .000 \\
\hline Nof Valid Cases & 100 & & \\
\hline
\end{tabular}

Figure 2. Crosstab Analysis

Crosstab analysis is the method to find statistically the relationship between two variables in details. In this research, a crosstab analysis has been conducted to test the relationship between the challenge to the bank's ability to drive through digital transformation with automation and employees' work efficiency which are the two variables that been tested as the hypothesis.

The below figure shows the relationship between the challenge to the bank's ability to drive through digital transformation with automation and employees' work efficiency. The results are statistically significant as Pearson Chi-Square value $=.000$ which is $<0.05$ and for that the null hypothesis will be rejected and the alternative hypothesis will be considered as there is indeed a statistically significant association between the challenge to the bank's ability to drive through digital transformation with automation and employees' work efficiency.

In summary, we can conclude statistically that automation can strongly achieve the improvement of employees' work efficiency through overcoming the lack of investment and the complexity to the current state/legacy environment challenges as it indicates the total value is $38 \%$. Additionally, automation can achieve the improvement of employees' work efficiency through overcoming the resource availability \& appropriate skills challenge as it indicates the total value is $42 \%$. In total 
$80 \%$, we can say that statistically, automation can increase employees' work efficiency by overcoming of three challenges which are lack of investment, the complexity to the current state/legacy environment and resource availability \& appropriate skills challenges.

\title{
Regression Analysis
}

\author{
REGRESSION \\ NARABLES $=$ Q7 \\ IDEPENDENT $=Q 9$ \\ /METHOD=EITER \\ /STATISTICS=COEFF RANOVA.
}

\section{Model Summary (Do you agree or disagree with the following statement: Automation will increase employees' work efficiency)

\begin{tabular}{|r|r|r|r|}
\hline$R$ & R Square & Adjusted R Square & Std. Error of the Estimate \\
\hline \hline .94 & .89 & .88 & .31 \\
\hline
\end{tabular}

ANOVA (Do you agree or disagree with the following statement: Automation will increase employees' work efficiency)

\begin{tabular}{|l|r|r|r|r|r|}
\hline \hline & Sum of Squares & df & Mean Square & F & Sig. \\
\hline \hline Regression & 70.63 & 1 & 70.63 & 756.04 & .000 \\
Residual & 9.16 & 98 & .09 & & \\
Total & 79.79 & 99 & & & \\
\hline
\end{tabular}

Coefficients (Do you agree or disagree with the following statement: Automation will increase employees' work efficiency)

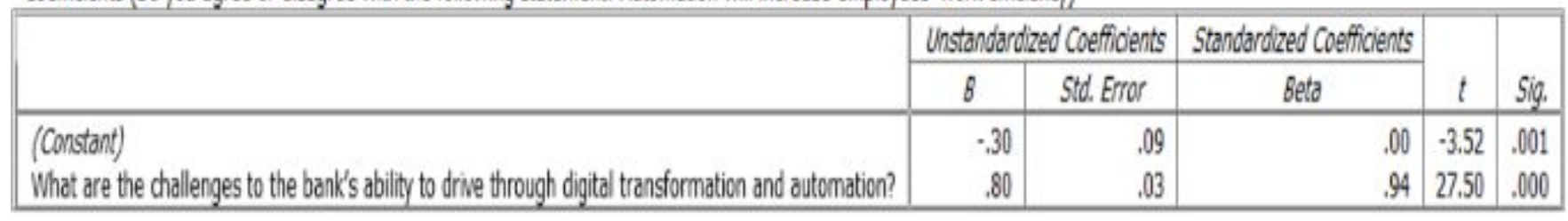

Figure 3. Regression Analysis

Regression analysis is a powerful statistical analysis that used to predict the relationship between variables. In this research, regression analysis has been conducted for the below hypothesis to predict the relationship between the independent variable the challenge to drive through digital transformation with automation) and the depended variable (employees' work efficiency).

The results show that there is a linear regression. Additionally, ANOVA results in statistically significant results as $F(1,98)=756.04, p=.000$ the $p$-value is $<0.05$ and for that the null hypothesis will be rejected and the alternative hypothesis will be considered as there is indeed statistically significant relationship between the challenge to the bank's ability to drive through digital transformation with automation and employees' work efficiency.

\section{Conclusions and Recommendations}

\section{Conclusions}

The conclusions are discussed based on each research objectives as per below:

Research objective 1: To find the requirements for developing Robotic Process Automation (RPA) at Bank Muscat. 


\section{Journal of Student Research}

Fourth Middle East College Student Research Conference, Muscat, Sultanate of Oman

To develop any new technology, it is required to spread the knowledge of the same and how it would benefit the current situation. As seen from the research survey, a large number of people are not familiar with RPA concept and its usage. Initiating RPA within the bank requires to determine a manageable scope. This scope can be determined from the process that would be chosen to be automated. Analyzing the current processes running in the bank is a significant start for RPA development. Analyzing the processes will require to determine the weakness, or the pain was the bank is looking to eliminate. According to the definition of RPA and its capabilities that been discussed in the literature reviews, the significant use of RPA is to automate manual, repetitive and structured tasks. additionally, RPA would be great solution to automate the process that runs under high volume of data and the tasks that consume by the users. From the research survey, around $50 \%$ of the employees are dealing with high volume of data every day and as a bank the number of data for processing will increase to serve a greater number of customers. Also, from the research survey, showed that employees daily operational work is involved with manual, structured and repetitive tasks in varies percentage that reached from $35 \%$ to $65 \%$. Thus, the important requirement to develop RPA is to define and analyze the right process that suites to be automated with RPA since it consumes the employees time, it is repetitive structured manual boring task. As seen from the research survey, the most tasks that consume time for the employees is data reconciliation and validation and for the same the application of RPA in reconciliation and reporting has been proven from the literature reviews on the significant impact on clearing breaks or expectations and update the correct data. Also, the research survey results showed that inputting/filling data within the application is also the second most task that consume time while accessing the applications and for the same proved by the literature reviews the application of RPA can be used in client servicing, reference, and static data management as these tasks require inputting data manually into application. From the bank perspective, back-office operational is looking to automate ATM/CDM dispute process through reconciliation, MIS report generation, account closure, and system integration. These areas been raised by Manager of Special Projects and Initiatives in Change Management Department at Bank Muscat based on the analysis and the need for initiating new projects for the improvement of the efficiency of back-office operational. Another requirement to start developing RPA within the bank is to investigate on the available vendors that offer RPA services for back-office operational. This step will come after analyzing the current processes which require to be automated. From the literature reviews, there were many of RPA vendors discussed on their services. The top popular vendors are Blue Prusim, UiPath and Automation Anywhere. The multiple vendors been discussed in the interview as well and the bank should start adopting RPA based on the problem and the available vendors that would provide the service that resolves the problem.

Research objective 2: Analyze the challenges of developing Robotic Process Automation (RPA) within Bank Muscat

As seen from the research survey, the challenges that the bank is facing while driving through digital transformation and automation is been responded in highly percentage $43 \%$ due to resource availability \& appropriate skills. This challenge has been discussed in the literature reviews as the bank should build the appropriate skills from IT department perspective as both IT department staff, and business users should collaborate in developing the successful use case for RPA. The other highlighted challenges from the research survey are complexity to the current state/legacy environment. This challenge has been discussed in detail while interviewing the manager of Special Projects and Initiatives from Bank Muscat. The complexity of bank Muscat situation to develop RPA mainly concerned on the current environment that is running under privacy and lots of IT-securities limitations. Also, the way Bank Muscat is dealing with vendors is centralized and not align with what market is providing as RPA cannot be used for complex processes unless to have different RPA vendors that provide plugins and integrate with each other so to deal with multiple vendors Bank Muscat is avoiding and it being as an obstacle to starting automating back-office operation processes. Bank Muscat can look in this case for a customizing solution which is hard to find within the solutions provided by RPA vendors. Moreover, RPA can be used sufficiently for rule-based structured tasks and as it is not intelligent to make decisions. This make the bank to first look and 


\section{Journal of Student Research}

Fourth Middle East College Student Research Conference, Muscat, Sultanate of Oman

make analysis for the suitable processes that RPA can be developed on and think about user interface actions as it will be eliminated because RPA works in the backend and won't be present in front-end to provide actions to the users in the middle then again continue the rest of the process automatically. This is to be considered as weakness in developing RPA within the bank.

Research objective 3: Study the implication of developing Robotic Process Automation (RPA) for Bank Muscat staff and customers

The implication of developing RPA within Bank Muscat can be summarized from its benefits that would provide for both bank's employees and their customers. As seen from the literature reviews, RPA can help in reducing operational cost and improve profitability. By shifting the manual processes to automation, there would be no need to move the processes offshore, so control will be maintained also RPA can operate full time and make less mistake than humans. Automating will eliminate the need for additional resources and time. This been agreed by the respondent of the survey as most of the employees are dealing with a high volume of tasks every day. Also, by 35\% the employees are working on repetitive structured tasks on their daily operations. So, if these tasks been automated, the employees would have more time to focus on strategic tasks that would add more value to the bank. 76\% of the survey responded agreeing and forecasting increase in banks profit by developing RPA. Moreover, RPA would increase accuracy while processing data since it is fully automated, and no human intervention is required. The same has been agreed by survey respondents and the manager of Bank Muscat as he convinced that if the employees are out of repetitive manual tasks stress, the number of human errors will be reduced even if the processed data increased over years. Moreover, RPA is easy to configure and can be integrated with the existing systems without any programming skills required and users can be trained within few weeks. From employees' efficiency perspective, RPA would increase the level of operational efficiency, as it would help in increasing accuracy, solve IT problems through monitoring and reporting. Also, RPA would execute the processes in speedily. Additionally, $80 \%$ of the survey respondents agreed on the automation effects on employee's efficiency. In this research, hypothesis has been built to prove the relationship between the challenge to the bank's ability to drive through digital transformation with automation and employees' work efficiency. From the analysis that been done, it is showing a statistically significant relationship between the same. So, we can conclude that by overcoming the challenges process bank operation through automation, employee's efficiency will be improved as automation will help the employees to focus on delivering high quality of products/services and understand the customers more which will enhance customer experience.

Research objective 4: To find the process to train the employees for the using of Robotic Process Automation (RPA) within Bank Muscat applications. From the literature reviews, survey respondents and interview, the training process can be followed by the bank as per below:

1. IT department and business users should be engaged in the process of developing RPA to understand the use, importance and the value that RPA will add for their daily work as this will provide a confidant for the users to accept the RPA as new technology

2. Simplifying the design of automation would be easy to train any new joiner to the bank.

3. Provides continues training for employees.

4. Creating a center of excellence would be important for organizations that would like to expand its experience with RPA that will be focused to improve employees' skills to configure, install, and integrate RPA within human workflow.

\section{Recommendations}

Below are the recommendations to develop RPA for BankMuscat back-office operations efficiency:

1. The knowledge of RPA should stablish as it is important to build a strong business case that would support the developing RPA or any new technology. 


\section{Journal of Student Research}

Fourth Middle East College Student Research Conference, Muscat, Sultanate of Oman

2. To identify the right processes to be automated that would provide the maximum benefits to the bank and impact revenues and costs.

3. To select the processes which are easy to automate, such as rule-based, structured, mature process with error-prone especially human errors and have few exceptions.

4. To convince the management and related functions such as the IT department and change management department for the change to start automating the bank's processes.

5. To simplify the design of automated processes to be understandable and require less effort for programming.

6. To study the challenges of developing RPA and start the fundamental change to drive the back-office operational processes through digitalization and automation that involves studying the current environment, investment and build appropriate skills for the resources.

7. To study the successful implementation of RPA internally and globally and seek a competitive advantage over competitors through the successful significant implementation of automation within back-office operational processes

8. To choose the right RPA vendor/provider and understand what market is providing to pick the best solution that would suites the bank from its processes, policies, security, and limitations.

9. To involve the human resource department in the initial stage of developing RPA to establish training for the employees and new programs related, so they would be empowered to maintain RPA and learn more about it expanded functionalities.

10. To understand and analyze the value propositions of developing RPA within the bank and maintaining big data, since RPA would help in generating clean understandable data. RPA data can be used for big data analytics to make decisions and understand customers, business trends and internal business processes.

11. To seek to understand customers and provide a high quality of products/services through automation of back-office operational and move toward front-office and work on the bank's strategic planning and growth.

\section{References}

Accenture. (2018). Back Office, It's Time to Meet the Customers . North America: 2018 North America Banking Operations Survey.

BANK, K. (2017). Annual Report 2017. Amsterdam: KAS BANK N.V.

BB\&T. (2017). Annual Report 2017. Charlotte, North Carolina: BB\&T Corporation (Branch Banking and Trust Company).

BHATIA, M. (2018). Your Guide to Qualitative and Quantitative Data Analysis Methods. Retrieved July 28, 2019, from https://humansofdata.atlan.com/2018/09/qualitative-quantitative-data-analysismethods/\#Analyzing_Quantitative_Data

C. Lacity, M., \& P. Willcocks, L. (2016). Robotic Process

Automation at Telefónica O2. MIS Quarterly Executive, 15(1), p21-35.

C.R.Kothari. (1990). Research Metho. In 2. nd (Ed.), Meaning of Research (p. 1). New Delhi: New Age International Publishers.

California, U. o. (2019). Organizing Your Social Sciences Research Paper: Types of Research Designs. Retrieved July 29, 2019, from https://libguides.usc.edu/writingguide/researchdesigns

CheckMarket. (2019). Sample size calculator. Retrieved July 30, 2019, from

https://www.checkmarket.com/sample-size-calculator/ 


\section{Journal of Student Research}

Fourth Middle East College Student Research Conference, Muscat, Sultanate of Oman

Corporation, B. (2019). BB\&T to invest up to $\$ 50$ million in fintech companies . Retrieved June 8, 2019, from https://bbt.mediaroom.com/2018-01-16-BB-T-to-invest-up-to-50-million-in-fintechcompanies

Dudovskiy, J. (2019). Data Collection Methods. Retrieved August 3, 2019, from https://researchmethodology.net/research-methods/data-collection/

Griviței, C. (2018). Setting Up a Robotic Process Automation Center of Excellence. Management Dynamics in the Knowledge Economy, 6(2), 307-322.

Hallikainen, P., Bekkhus, R., \& L. Pan, S. (2018). How OpusCapita Used Internal RPA Capabilities to Offer Services to Clients. MIS Quarterly Executive, 17(1), 41-52.

Hegde, S., Gopalakrishnan, S., \& Wade, M. (2017). Robotics in securities operations. Journal of Securities Operations \& Custody, 10(1), 29-37.

Hundley, E. R. (2001). The importance of pilot studies. Guildford, England : Department of Sociology, University of Surrey.

Hyeonyounggeun, \& Yijuyeon. (2018). Trends Analysis and Future Direction of Business Process Automation, RPA (Robotic Process Automation) in the Times of Convergence. Journal of Digital Convergence, 16(11), 313-327.

IBM. (2019). What is robotic process automation (RPA)? Retrieved July 13, 2019, from https://www.ibm.com/products/robotic-process-automation

Issac, R., Muni, R., \& Desai, K. (2018). Delineated Analysis of Robotic Process Automation. Second International Conference on Advances in Electronics, Computer and Communications, 5.

KAYA, C., TURKYILMAZ, M., \& BIROL, B. (2019). Impact of RPA Technologies on Accounting Systems. Journal of Accounting \& Finance(82), p235-249.

KRUSKOPF, S., LOBBAS, C., MEINANDER, H., SÖDERLING1, K., MARTIKAINEN1, M., \& M LEHNER, O. (2019). DIGITAL ACCOUNTING: OPPORTUNITIES, THREATS AND THE HUMAN FACTOR. ACRN Journal of Finance and Risk Perspectives, 8, 1-15.

M. Rozario, A., \& A. Vasarhelyi, M. (2018). How Robotic Process Is Transforming Accounting and Auditing. CPA Journal, 88(6), 46-49.

Madakam, S., M. Holmukhe, R., \& Jaiswal, D. K. (2019). The Future Digital Work Force: Robotic Process

Automation (RPA). Revista de Gestão da Tecnologia e Sistemas de Informação / Journal of Information Systems \& Technology Management, 16(1807-1775), p1-17.

Partnership, L. C. (2019). Robotics in Banking with 4 RPA Use Case Examples. Retrieved June 17, 2019, from https://thelabconsulting.com/robotics-in-banking-with-4-rpa-use-case-examples/

Parvez, F., \& Agaram, H. (2019). what challeges are organization facing in developing RPA? Retrieved Auguest 21, 2019, from https://robotic-process-

automation.cioadvisorapac.com/cioviewpoint/what-challenges-are-organizations-facing-in-deployingrpa-nwid-506.html

Pega. (2019). Pega Customers. Retrieved June 23, 2019, from https://www.pega.com/customers/bbt 


\section{Journal of Student Research}

Fourth Middle East College Student Research Conference, Muscat, Sultanate of Oman

Seasongood, S. (2016). A Case for Robotics in Accounting and Finance. FINANCIAL EXECUTIVE.

SHOJAI, S. (2017). AUTOMATION. THE CAPCO INSTITUTE JOURNAL OF FINANCIAL TRANSFORMATION.

Station, I. C. (2019). Robotic Process Automation Software Vendors Comparison - RPA Tools Comparison. Retrieved July 20, 2019, from https://www.itcentralstation.com/categories/roboticprocess-automation-rpa

SunTrust. (2017). Annual Report 2017. Atlanta. US: SunTrust Banks.

Tavakol , M., \& Dennick, R. (2011). nternational Journal of Medical Education, 2, 53-55.

Wren, C. P. (2005-06). EXPLORING RELIABILITY IN ACADEMIC ASSESSMENT. UNI Office of Academic 